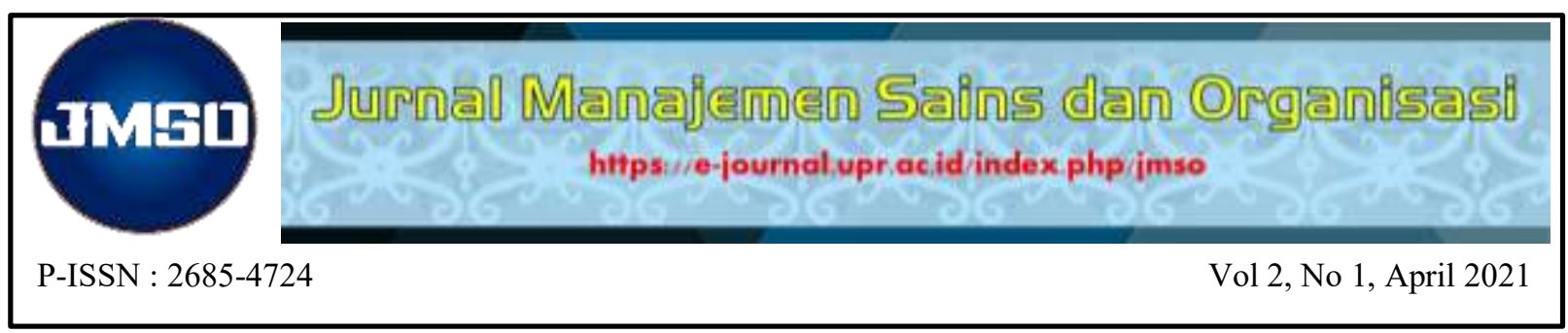

\title{
ANALISIS IMPLEMENTASI SISTEM JUST IN TIME (JIT) PADA PERSEDIAAN BAHAN BAKU UNTUK MEMENUHI KEBUTUHAN PRODUKSI PADA ZIDANE MEUBEL PALANGKA RAYA
}

\author{
Rina $^{1)}$, Achmad Syamsudin ${ }^{2)}$, Deddy Rakhmad Hidayat ${ }^{3)}$ \\ Fakultas Ekonomi dan Bisnis \\ Universitas Palangka Raya, Indonesia \\ e-mail: rinacenapcy@gmai.com,
}

\begin{abstract}
Abstrak
Tujuan, - Penelitian ini dilakukan bertujuan untuk mengetahui penggunaan metode persediaan bahan baku pada Zidane Meubel yang paling efektif, dengan membandingkan metode yang digunakan perusahaan untuk dengan metode Just In Time (JIT).

Desain/Methodologi/Pendekatan, - Penelitian ini menggunakan metode deskriptif kuantitatif sehingga menggambarkan data dengan angka-angka.

Temuan Penelitian, - Dari analisis menggunakan sistem Just In Time dapat disimpulkan bahwa sistem Just In Time lebih efisien dalam perhitungan total biaya persediaan Zidane Meubel. Penghematan biaya yang didapat sebesar Rp 2.095.684,71 dari persediaan awal Rp 2.900.000.
\end{abstract}

Kata Kunci : Persediaan, Bahan Baku, Biaya dan Just In time (JIT)

The analysis of just in time (JIT) System Implementation On Raw Material Inventory to Fulfill Production Needs in Zidane Meubel Palangka Raya

\begin{abstract}
Purpose, - This research was conducted to determine the most effective use of the raw material inventory method for Zidane Meubel, by comparing the method used by the company to the Just In Time (JIT) method.

Desain/methodology/appoach, - This study uses a quantitative descriptive method so that it describes the data with numbers.

Findings, - From the analysis using the Just In Time system, it can be concluded that the Just In Time system is more efficient in calculating the total cost of inventory Zidane Meubel.cost savings obtained were Rp 2.095.684,71 from initial invetory Rp 2.900.000.
\end{abstract}

Keywords: Inventory, Raw Materials, costs and Just In Time (JIT)

Jurnal Manajemen Sains dan Organisasi 2021 pp. 64 - 72
Rina,Achmad Syamsudin ' Deddy Rakhmad Hidayat. Published in the Jurnal Manajemen sains dan Organsasi. Published by FEB UPR Publishing Limited. This article is published under the Creative Commons Attribution (CC BY 4.0) licence. Anyone may reproduce, distribute, translate and create derivative works of this article (for both commercial and non-commercial purposes), subject to full attribution to the original publication and authors. 


\section{PENDAHULUAN}

Penelitian dan latar belakang, rumusan masalah penelitian, tujuan, manfaat penelitian, dan Kegiatan perusahaan mempunyai hubungan yang sangat erat dengan kegiatan produksi untuk memenuhi kebutuhan pasar. Untuk mengadakan kegiatan produksi dibutuhkan bahan baku yang merupakan masalah penting dalam proses produksi tersebut agar tidak terjadi keterlambatan bahan baku, maka harus diadakan penentuan sistem persediaan bahan baku memiliki peranan penting di dalam operasi bisnis. Bahan baku merupakan faktor utama di dalam perusahaan untuk menunjang kelancaran proses produksi, baik perusahaan besar maupun perusahaan kecil.

Setiap perusahaan selalu mengadakan persediaan agar kelangsungan proses produksi perusahaan tidak terganggu. Tetapi ada juga suatu sistem persediaan bahan baku yang tidak mengandalkan pada penyimpanan persediaan dengan jumlah yang banyak. Pengendalian pada persediaan bahan baku berpengaruh pula pada laba yang akan diperoleh perusahaan. Metode persediaan tepat waktu (just in time) adalah metode yang paling tepat digunakan dalam pengendalian persediaan bahan baku pembantu karena metode ini adalah metode terbaru yang dipusatkan untuk mengurangi biaya melalui eliminasi persediaan.

Just in Time (JIT) adalah suatu sistem produksi yang dirancang untuk mendapatkan kualitas, menekan biaya, dan mencapai waktu penyerahan seefisien mungkin dengan menghapus seluruh jenis pemborosan yang terdapat dalam proses produksi sehingga perusahaan mampu menyerahkan produknya (baik barang maupun jasa) sesuai kehendak konsumen tepat waktu. Untuk mencapai sasaran dari sistem ini, perusahaan memproduksi hanya sebanyak jumlah yang dibutuhkan atau diminta konsumen dan pada saat dibutuhkan sehingga dapat mengurangi biaya pemeliharaan maupun menekan kemungkinan kerusakan atau kerugian akibat menimbun barang. Sistem persediaan Just in Time (JIT) dapat membantu manajer untuk menggunting biaya, meningkatkan biaya, meningkatkan efisiensi, dan memperluas keluaran.

Salah satu perusahaan yang bergerak di bidang furnitur yang bisa dijadikan sasaran implementasi sistem persediaan JIT (Just in Time) adalah Zidane Meubel Palangka Raya bergerak di bidang pembuatan produk-produk furniture atau perlengkapan rumah tangga. Produk yang dihasilkan oleh Zidane Meubel adalah seperti kursi, meja, dan lemari.

\section{KAJIAN PUSTAKA \\ Persediaan Bahan Baku}

Persediaan (inventory) adalah stock atau simpanan barang-barang yang ada diperusahaan (Stevenson, 2014). Bahan baku merupakan barang-barang yang dibeli dari pemasok (supplier) dan akan digunakan atau diolah menjadi produk jadi yang akan dihasilkan oleh perusahaan. (Sofyan, 2013). Tanpa persediaan bahan baku, maka suatu perusahaan tidak akan berjalan sistem produksinya. Bahan baku di dalam perusahaan digunakan sebagai bahan yang akan diolah menjadi barang jadi melalui proses produksi. Di dalam sistem Just in Time (JIT) ditujukan untuk menerapkan membeli persediaan barang hanya dalam kuantitas yang dibutuhkan saja.

\section{Biaya dalam Persediaan}

Kegiatan operasional perusahaan yang berhubungan dengan persediaan, pastinya akani ditemukan masalah biaya-biaya yang berkaitan dengan persediaan. Biaya merupakan pengorbanan yang dilakukan perusahaan untuk memperoleh barang/jasa. Simamora (2012) mengungkapkan bahwa "biaya (cost) adalah kas atau setara kas yang dikorbankan 
(dibayarkan) untuk barang atau jasa yang diharapkan memberikan manfaat (pendapatan) pada saat ini atau dimasa depan bagi perusahaan". Menurut Ristono biaya persediaan meliputi:

1) Biaya pembelian

2) Biaya pemesanan

3) Biaya penyimpanan

4) Biaya kekurangan persediaan

\section{Sistem Just In Time (JIT)}

Menurut Ishak (2010) secara sederhana mendeskripsikan Just In Time hanya permintaan unit yang dibutuhkan tersedia dalam jumlah yang dibutuhkan dan pada saat dibutuhkan, dengan logika dasar pemikiran Just In Time adalah "Tidak ada yang akan di produksi sampai ia dibutuhkan". Wijaksono (2013) mengungkapkan Just In Time (JIT) adalah suatu filosofi bisnis yang khusus membahas bagaimana mengurangi waktu produksi, baik dalam proses menufaktur maupun proses nonmanufaktur. Adapun delapan kunci utama dalam pelaksanaan Just In Time dalam kegiatan industri (Sulastri, 2012), yaitu:

a. Menghasilkan produk sesuai permintaan konsumen.

b. Memproduksi dalam jumlah kecil.

c. Menghilangkan pemborosan.

d. Memperbaiki aliran produksi.

e. Menyempurnakan kualitas produk.

f. Orang-orang yang tanggap.

g. Menghilangkan ketidak pastian.

h. Penekanan pada pemeliharaan jangka panjang.

Banyak kelebihan yang dapat dinikmati dalam penerapan sistem Just In Time, diantaranya sebagai berikut:

1) Tingkat Persediaan atau Stock Level yang rendah sehingga menghemat tempat penyimpanan dan biaya-biaya terkait seperti biaya sewa tempat dan biaya asuransi.

2) Bahan-bahan produksi hanya diperoleh saat diperlukan saja sehingga hanya memerlukan modal kerja yang rendah.

3) Dengan tingkat persediaan yang rendah, kemungkinan terjadinya pemborosan akibat produk yang ketinggalan zaman, lewat kadaluarsa dan rusak atau usang akan menjadi semakin rendah.

4) Menghindari pengumpulan produk jadi yang tidak terjual akibat perubahan mendadak dalam permintaan.

5) Memerlukan penekanan pada kualitas bahan-bahan produksi yang dipasok oleh Supplier (Pemasok) sehingga dapat mengurangi waktu pemeriksaan dan pengerjaan ulang.

Meskipun banyak kelebihan yang bisa didapat, sistem produksi Just In Time ini masih memiliki kelemahan, yaitu:

1) Sistem produksi Just In Time tidak memiliki toleransi terhadap kesalahan sehingga akan sangat sulit untuk melakukan perbaikan atau pengerjaan ulang pada bahan-bahan produksi ataupun produk jadi yang mengalami kecacatan. Hal ini dikarenakan tingkat persediaan bahan-bahan produksi dan produk jadi yang sangat minimum.

2) Ketergantungan yang sangat tinggi terhadap pemasok baik dalam kualitas maupun ketetapan pengiriman yang pada umumnya diluar lingkup perusahaan manufacturing yang bersangkutan.

3) Keterlambatan pengiriman oleh satu pemasok dan akan mengakibatkan terhambatnya semua jadwal produksi yang telah direncanakan. Biaya transaksi akan relatif tinggi akibat 
frekuensi yang tinggi.

4) Perusahaan manufacturing yang bersangkutan akan sulit memenuhi permintaan yang mendadak tinggi pada kenyataannya tidak ada produk jadi yang lebih.

\section{Manfaat Metode Just In Time}

Manfaat potensi Just Int Time sangat banyak seperti, mengurangi tingkat persediaan, yang berarti investasi yang lebih rendah dalam persediaan. Karena sistem hanya memerlukan jumlah bahan terkecil yang dibutuhkan segera, maka secara substansial akan mengurangi keseluruhan tingkat persediaan sehingga pemborosan dalam hal persediaan tidak terjadi serta pembelian dibawah Just In Time memerlukan waktu pengiriman yang jauh lebih singkat, kendala lead-time sangat meningkat.

Manfaat lain dari Just In Time yaitu:

a. mengurangi investasi di pabrik untuk persediaan dan proses produksi,

b. Mengurangi resiko dalam persediaan,

c. Mengurangi ruang atau gudang untuk penyimpanan barang,

d. Mengurangi pemborosan barang rusak dan barang cacat dengan mendeteksi kesalahan pada sumbernya,

e. Mengurangi biaya bahan langsung melalui pebelian barang.

\section{Pemborosan pada Just In Time}

Menurut sofyan (2013) Pemborosan yang tidak memberikann nilai tambah (added value) pada produksi meliputi:

1) Produksi yang berlebih (Over Production)

2) Waktu menunggu (Waiting time)

3) Tranportasi (Transportation)

4) Proses yanga berlebih (Procesing)

5) Persediaan berlebih (inventory)

6) Gerakan yang tidak perlu (Motion)

7) Produk Cacat (Product Defect)

8) Kreatifitas karyawan yang tidak dimanfaatkan.

Persediaan dalam suatu perusahaan atau usaha dagang memiliki peran penting dalam menunjang jalannya suatu proses produksi. Apabila persediaan dalam suatu perusahaan dikelola dengan baik maka proses produksi pun dapat berjalan dengan lancar. Persediaan merupakan sumber daya organisasi yang disimpan dalam memenuhi kebutuhan produksi sesuai permintaan konsumen.

\section{Sasaran Implementasi Just In Time Produksi}

Edward dalam bukunya Haming (2012) mengungkapkan bahwa sasaran yang dituju dalam Just In Time meliputi:

1. Zero Defect

Pada pendekatan Just In Time, kegiatan produksi diarahkan untuk mencapai keluaran tanpa cacat, selesai pada waktunya, dan dengan jumlah yang tepat sesuai dengan permintaan. 2. Zero Inventories

Dalam pandangan Just In Time, persediaan dipandang sebagai pemborosan, karena dianggap kurang tepat dalam perencanaan pengadaan dan ketidaksesuaian antara pemasokan dan rencana kebutuhan akan sediaan. Dalam Just In Time, produksi dilaksanakan sesuai dengan permintaan yang ada sehingga voleme produksi selalu sama dengan volume permintaan.

3. Zero setup time and lot size of one 
Set-up time dan set-up cost sama dengan atau mendekati nol, maka lot size disebut lot size one. Komponen (bahan) diserahkan satu demi satu sesuai waktu yang dibutuhkan. Komponen dan subkomponen yang diperlukan selalu harus tersedia dan diserahkan ke unit perakitan sesuai jumlah yang butuhkan.

\section{Zero lead time}

Pemasok harus menyerahkan bahan dengan tepat waktu sehingga berakibat pada lead time yang minimal.

\section{Zero Part Handling}

Part Handling adalah kegiatan pemindahan part atau komponen dari satu stasiun ke stasiun kerja lainnya. Biaya pemindahannya tergantung pada jarak pemindahan komponen tersebut. Dalam Just In Time tata letak proses diubah menjadi tata letak hibrida, dimana semua alat atau mesin yang diperlukan untuk menyelesaikan satu jenis produk disatukan dalam ruangan yang sama sehingga jarak pemindahan komponen berdekatan, oleh karenanya waktu dan biaya pemindahan menjadi sangat minimal.

\section{Sistem Just In Time Produksi}

Sistem Just In Time produksi menunjukan sistem produksi dimana aktivitas operasi terjadi hanya diperlukan. Selain demikian berposisi sebagai alat pendekatan untuk penyeimbangan produksi, alat pengendali kualitas produk, dan mekanisme untuk motivasi serta keterlibatan para tenaga kerja. Just In Time produksi berarti memproduksi dam menebeli kuatitas yang sangat sedikit, pada saat yang tepat untuk digunakan. Just In Time produksi didasarkan pada logika bahwa akan memproduksi produk sampai ada permintaan untuk produk tersebut. Just In Time produk mengharuskan memproduksi secara tepat unit yang dibutuhkan, dalam jumlah dan waktu sesuai kebutuhan. Dalam kenyataannya, sesuatu yang melebihi jumlah kebutuhan minimum dipandang sebagai pemborosan sejak usaha dan bahan baku yang dikeluarkan untuk sesuatu yang tidak dibutuhkan sekarang tidak dapat dimanfaatkan sekarang.

Berdasarkan pembahasan diatas, maka dapat disusun kerangka pemikiran yang digambarkan sebagai berikut:

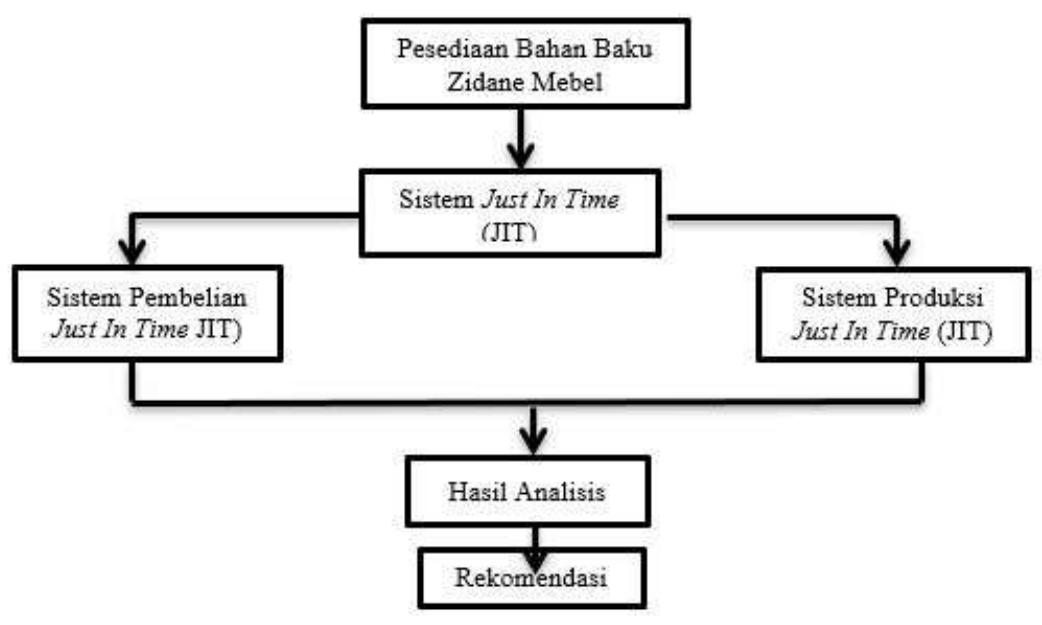

\section{Hipotesis}

Gambar 2.1 Kerangka Berpikir

Sugiyono (2017) berpendapat bahwa hipotesis adalah "jawaban sementara terhadap 
rumusan masalah penelitian, dimana rumusan masalah penelitian telah dinyatakan dalam bentuk kalimat pertanyaan". Jadi hipotesis adalah jawaban sementara terhadap masalah yang masih bersifat praduga karena masih harus dibuktikan kebenarannya, yang akan diuji kebenarannya dengan data yang dikumpulkan melalui penelitian.

Hipotesis penelitian ini adalah: "Diduga analisis implementasi metode Just In Tme (JIT) pada persediaan bahan baku dapat menghasilkan efisiensi biaya persediaan pada Zidan Meubel Palangka Raya".

\section{METODE PENELITIAN}

Penilitian ini menggunakan penelitian deskriptif dengan mengggunakan pendekatan kuantitatif yang bersifat studi kasus dengan pendekatan kuantitatif melalui pengumpulan data dari perusahaan dan menganalisis dengan sistem Just in Time. Sehingga dari hasil penelitian dapat ditarik kesimpulan yang dapat dipakai sebagai bahan pertimbangan dalam pengambilan keputusan di dalam memecahkan masalah perusahaan.

Teknik analisis data yang digunakan dalam penelitian ini yaitu dengan langkah sebagai berikut:

1) Mengumpulkan informasi mengenai jumlah persediaan bahan baku selama satu bulan.

2) Mengolah data-data tersebut untuk mengetahui optimalisasi pengendalian persediaan bahan baku berdasarkan kebijakan perusahaan. Dengan cara (Herjanto dalam Zubaidi, A. 2019):

a. Menghitung pembelian rata-rata bahan baku (Q)

$$
\mathrm{Q}=\frac{\text { Total Kebutuhan Bahan Baku }}{\text { Frekuensi Pesanan }}
$$

b. Menghitung total biaya persediaan (TIC)

$$
\mathrm{TIC}=\left(\frac{D}{Q}\right) S+\left(\frac{Q}{2}\right)
$$

Keterangan:

$\mathrm{D}=$ Permintaan bulanan persediaan dalam unit

$\mathrm{Q}=$ Jumlah barang setiap pemesanan

$\mathrm{S}=$ Biaya pemesanan untuk setiap pemesanan

3) Menganalisis data-data yang telah diolah tersebut menggunakan metode Just In Time.

Berikut metode yang digunakan untuk menghitung jumlah pemesanan optimal dan total biaya persediaan menggunakan metode Just In Time (Hayundra, 2013) :

a. Menetukan Jumlah Pengiriman Optimal Bahan Baku Metode JIT

$n a=\frac{Q}{2 a}$

Keterangan :

$\mathrm{Q}=$ Total Kebutuhan Bahan Baku

$\mathrm{a}=$ Persediaan rata-rata bahan baku

b. Menentukan Kuantitas Pemesanan Bahan Baku yang Optimal Metode JIT

$Q n=\sqrt{n} \mathrm{Q}^{*}$

Keterangan :

$\mathrm{n}=$ Jumlah pengiriman bahan baku

$\mathrm{Q}^{*}=$ Kuantitas pesanan optimal EOQ 
c. Menentukan kuantitas pengiriman yang optimal untuk setiap kali pengiriman bahan baku metode JIT.

$q=\frac{Q n}{n}$

Keterangan :

Qn = Kuantitas pemesanan bahan baku optimal

$\mathrm{n}=$ Jumlah pengiriman optimal

d. Menentukan Frekuensi Pemesanan Bahan Baku Metode JIT

$N=\frac{Q n}{n}$

Keterangan :

$\mathrm{Q}=$ Total kebutuhan bahan baku

Qn $=$ Kuantitas pemesanan bahan baku optimal

$\mathrm{n}=$ Jumlah optimal pengiriman selama satu periode

e. Menghitung Biaya Persedian Bahan Baku

$T J I T=\frac{1}{\sqrt{n}}(T)$

Keterangan :

$\mathrm{T}=$ Total biaya persediaan bahan baku

$\mathrm{n}=$ Jumlah pengiriman optimal

\section{Hasil Penelitian}

Sebelum diadakan analisa menggunakan metode Just In Time (JIT), maka perlu diketahui terlebih dahulu metode yang digunakan oleh perusahaan, yang mana metode tersebut akan dibandingkan dengan metode Just In Time (JIT) untuk mengetahui keefektifan metode tersebut bila diterapkan.

Tabel 6. Hasil Perbandingan Pengendalian Persediaan Bahan Baku antara Kebijakan Perusahaan dan Metode JIT

\begin{tabular}{|l|c|c|}
\hline \multicolumn{1}{|c|}{ Keterangan } & Kebijakan Perusahaan & Metode JIT \\
\hline Kebutuhan Bahan Baku Per Bulan & 705 Lembar & 705 Lembar \\
\hline Kuantias Pemesanan Optimal & 176,25 Lembar & 141 Lembar \\
\hline Frekuensi Pemesanan Per Bulan & 4 Kali & 5 Kali \\
\hline $\begin{array}{l}\text { Frekuensi Pengiriman per pesan selama satu } \\
\text { minggu } \\
\text { (jumlah pengiriman optimal bahan baku dibagi } \\
\text { frekuensi pemesanan per bulan) }\end{array}$ & $(4: 4)=1$ Kali & $(13: 5)=2,6$ (3 Kali) \\
\hline Total Biaya Persediaan & Rp 2.900.000 & Rp 804.315,28 \\
\hline
\end{tabular}

Sumber: Data Primer diolah (2021) 


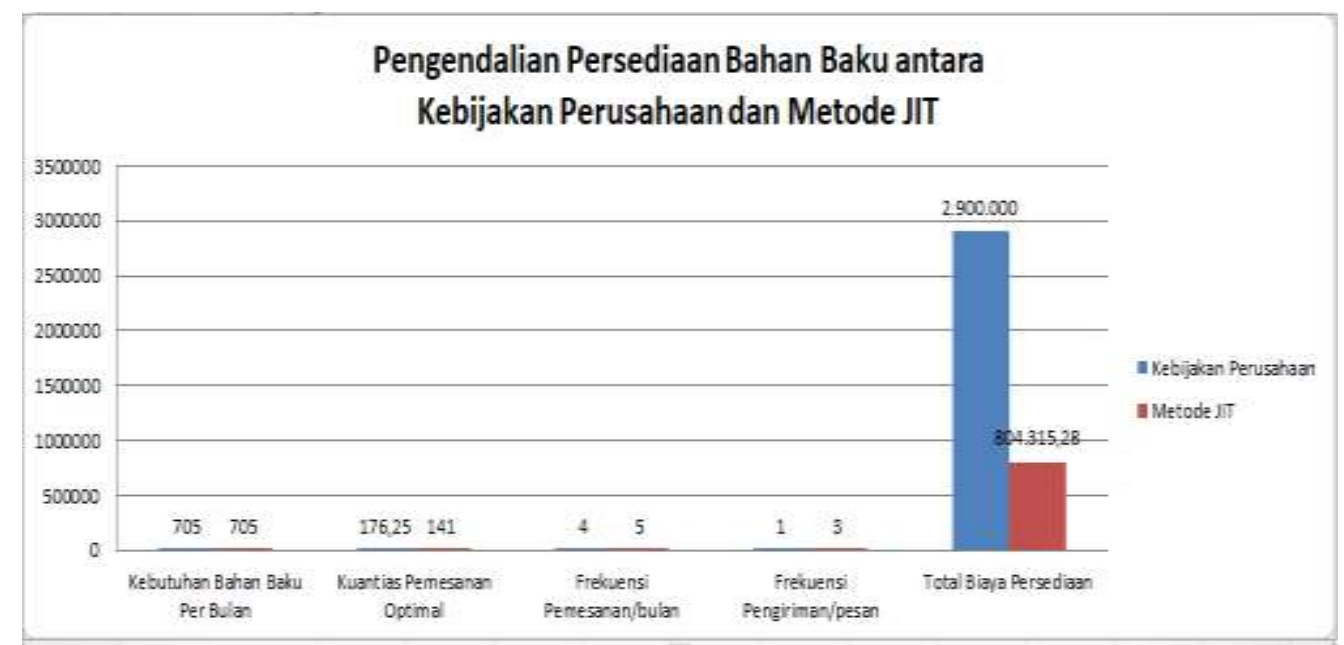

Sumber: Data primer diolah (2021)

Gambar 2. Grafik Pengendalian Persediaan antara Kebijakan Perusahaan dan JIT

Dari tabel 4.6 dan grafik 4.1 diatas terlihat perbandingan pengendalian persediaan bahan baku kayu papan antara kebijakan yang telah digunakan oleh Zidane Meubel dengan metode Just In Time (JIT), dapat diketahui bahwa kebutuhan bahan baku sebesar 705 lembar. Kemudian pembelian rata-rata bahan baku berdasarkan kebijakan perusahaan sebesar 176,25 lembar sedangkan apabila menggunakan metode Just In Time (JIT) kuantitas pemesanan yang optimal sebesar 141 lembar. Untuk memenuhi kebutuhan bahan baku dengan kuantitas pemesanan yang optimal maka dengan metode Just In Time (JIT) dapat dilakukan 5 kali pemesanan bahan baku, jumlah ini lebih banyak dibandingkan dengan kebijakan perusahaan yang hanya 4 kali pemesanan. Kemudiaan total biaya persediaan yang dikeluarkan berdasarkan kebijakan perusahaan Rp 2.900.000. sedangkan apabila menggunakan metode Jus In Time (JIT) maka total biaya persediaan bahan baku sebesar Rp 804.315,28. Apabila dibandingkan dengan kebijakan perusahaan maka dapat dilakukan penghematan biaya persediaan sebesar Rp 2.095.684,71. Sehingga dalam usaha meningkatkan efisiensi biaya persediaan bahan baku perusahaan dapat menggunakan metode Just In Time (JIT), pembelian di lakukan dalam jumlah yang kecil dan pengiriman secara berkala, sehingga dapat menekan terjadinya biaya penyimpanan bahan baku.

\section{Kesimpulan}

1. Total biaya persediaan yang dikeluarkan berdasarkan kebijakan perusahaan Rp 2.900.000. sedangkan apabila menggunakan metode Jus In Time (JIT) maka total biaya persediaan bahan baku sebesar Rp 804.315,28. Apabila dibandingkan dengan kebijakan perusahaan maka dapat dilakukan penghematan biaya persediaan sebesar Rp 2.095.684,71.

2. Dalam menganalisis perbandingan metode Just In Time (JIT) dan kebijakan perusahaan dengan data persediaan bahan baku yang ada di Zidane Meubel dilakukan dengan perhitungan rumus Just In Time (JIT) untuk mengukur perbandingan nilai dengan metode tersebut.

3. Untuk mengetahui hasil dari perhitungan persediaan bahan baku menggunakan metode Just In Time (JIT) lalu dibandingkan dengan kebijakan perusahaan, manakah yang lebih tepat. 
4. Dalam usaha meningkatkan efisiensi biaya persediaan bahan baku perusahaan dapat mengunakan metode Just In Time (JIT), pembelian dilakukan dalam jumlah yang kecil dan pengiriman secara berkala, sehingga dapat menekan terjadinya biaya penyimpanan.

\section{REFERENSI}

Haming, M. \& Nurnajarnuddin, M. (2012). Manajemen Produksi Modern (edisi 2). Jakarta: Salemba Empat.

Hansen. \& Mowen. (2009). Managerial Accounting. Jakarta: Salemba Empat.

Hayundra, M, m,. \& Kamal, M. (2015). Perbandingan Sistem Economic Order dan Just In Time Pada Pengendalian Persediaan Bahan Baku. Diponegoro Journal of Management Volt 4 No.2, 1-14.

Ishak, A. (2010). Manajemen Operasi. Yoyagkarta: Graha Ilmu.

Ristono, Agus. (2009). Sistem Produksi Tepat Waktu. Yogyakarta: Graha Ilmu.

Sekunder. W, H. (2011). Penerapan Just In Time Dalam Sistem Pembelian dan Sistem Produksi. Binus Business review Vol. 2 No. 1 Mei: 446-445.

Simamora, H. (2012). Akuntasi Manajemen. Riau: Star Gate Publisher

Sofyan, Diana K. (2013). Perencanaan dan Pengendalian Produksi. Yoyagkarta: Graha Ilmu.

Stevenson, W. J. \& Chuong, S. C. (2014). Manajemen Operasi Perpektif Asia. Jakarta: Salemba Empat.

Sugiyono. (2017). Metode Penelitian Kuantitatif, Kualitatif, dan R\&D. Bandung: Alfabeta, CV.

Sulastri, P. (2012). Sistem Just In Time Penting Bagi Perusahaan Industri. Jurnal Dharma Ekonomi No. 36/Th.XiX/Oktober 2012.

Witjaksono, A. (2013). Akuntasi Biaya (edisi revisi). Yoyagkarta: Graha Ilmu.

Zubaidi, A. (2019). Penerapan Metode Just In Time Sebagai Alternatif Pengendalian Persediaan Bahan baku Pabrik Sepatu Pass Clasik Pati. Skripsi Universitas Institut Agama Islam Negeri Surakarta. 